\title{
Article
}

\section{Hierarchical porous TiO2 single crystals templated from partly glassified polystyrene}

Guo, Hongli, Sen, Tapas, Zhang, Jinlong and Wang, Lingzhi

Available at http://clok.uclan.ac.uk/25471/

Guo, Hongli, Sen, Tapas ORCID: 0000-0002-0463-7485, Zhang, Jinlong and Wang, Lingzhi (2019) Hierarchical porous TiO2 single crystals templated from partly glassified polystyrene. Journal of Colloid and Interface Science, 538 . pp. 248-255. ISSN 0021-9797

It is advisable to refer to the publisher's version if you intend to cite from the work. http://dx.doi.org/10.1016/j.jcis.2018.11.067

For more information about UCLan's research in this area go to http://www.uclan.ac.uk/researchgroups/ and search for < name of research Group>.

For information about Research generally at UCLan please go to http://www.uclan.ac.uk/research/

All outputs in CLoK are protected by Intellectual Property Rights law, including Copyright law. Copyright, IPR and Moral Rights for the works on this site are retained by the individual authors and/or other copyright owners. Terms and conditions for use of this material are defined in the policies page.

\section{CLoK}

Central Lancashire online Knowledge www.clok.uclan.ac.uk

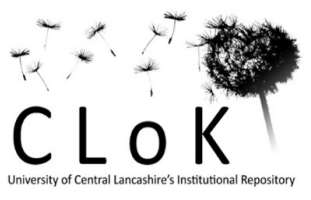




\section{Accepted Manuscript}

Hierarchical porous $\mathrm{TiO}_{2}$ single crystals templated from partly glassified polystyrene

Hongli Guo, Tapas Sen, Jinlong Zhang, Lingzhi Wang

PII: S0021-9797(18)31381-X

DOI: https://doi.org/10.1016/j.jcis.2018.11.067

Reference: YJCIS 24332

To appear in:

Journal of Colloid and Interface Science

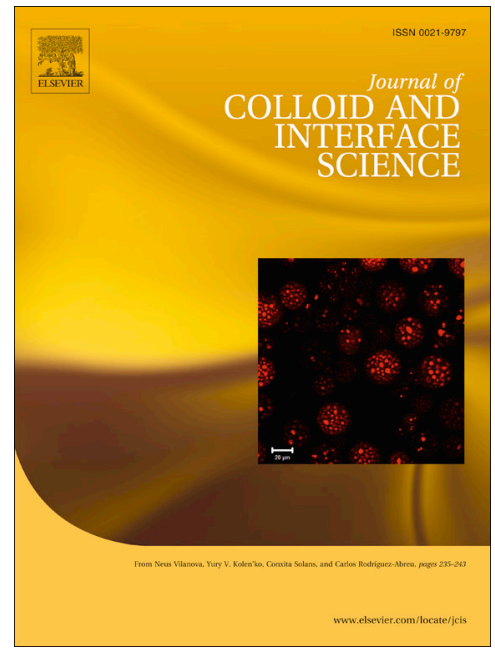

Received Date:

15 August 2018

Revised Date:

13 November 2018

Accepted Date:

15 November 2018

Please cite this article as: H. Guo, T. Sen, J. Zhang, L. Wang, Hierarchical porous $\mathrm{TiO}_{2}$ single crystals templated from partly glassified polystyrene, Journal of Colloid and Interface Science (2018), doi: https://doi.org/10.1016/ j.jcis.2018.11.067

This is a PDF file of an unedited manuscript that has been accepted for publication. As a service to our customers we are providing this early version of the manuscript. The manuscript will undergo copyediting, typesetting, and review of the resulting proof before it is published in its final form. Please note that during the production process errors may be discovered which could affect the content, and all legal disclaimers that apply to the journal pertain. 


\section{Hierarchical porous $\mathrm{TiO}_{2}$ single crystals templated}

\section{from partly glassified polystyrene}

Hongli Guo, ${ }^{1}$ Tapas Sen, ${ }^{2}$ Jinlong Zhang, ${ }^{1}$ Lingzhi Wang ${ }^{1 *}$

${ }^{1}$ Key Lab for Advanced Materials and Institute of Fine Chemicals, East China University of

Science and Technology, 130 Meilong Road, Shanghai, China

${ }^{2}$ School of Physical Sciences \& Computing, Centre of Materials Sciences, University of Central

Lancashire, Preston, UK

Abstract: Hierarchical macro-mesoporous anatase $\mathrm{TiO}_{2}$ single crystal is one-pot synthesized in an EtOH- $\mathrm{H}_{2} \mathrm{O}$ system using polystyrene (PS) as the single porogen both for macropore and mesopore and $\mathrm{TiF}_{4}$ as the titanium precursor. The key to the simultaneous growth of single crystal and the introduction of hierarchical pores is the assembly of PS and titania at the glassification temperature of $\mathrm{PS}\left(100{ }^{\circ} \mathrm{C}\right)$. During the hydrolytic polymerization of $\mathrm{TiF}_{4}, \mathrm{PS}$ is encapsulated inside titania and gradually glassified. The interference from elastic PS on the oriental growth of $\mathrm{TiO}_{2}$ crystallite is thus minimized and the final removal of PS through calcination leaves interconnected macropore and mesopore inside the single crystal. According to XPS, EPR and fluorescence analyses, abundant oxygen vacancies are formed on the hierarchical porous single crystal, which presents extraordinary photocatalytic activity and stability in degrading organic pollutants under simulated sunlight irradiation using Rhodamine B 
as the model. The improved photocatalytic activity is a synergistic effect of improved separation of charge carrier and facilitated interfacial charge transfer benefitting from highly accessible porous single crystal structure.

Keywords: hierarchical porous $\mathrm{TiO}_{2}$, single crystal, charge transfer, oxygen vacancy, photocatalysis

In the past decades, environmental issues have drawn an increasing attention due to the severe worldwide pollution issues [1-3]. Hence, as one of the most promising oxidation technology for pollutants elimination, photocatalysis has received considerable attention and has experienced prosperous advances [4-7]. Intensive effort has been devoted to developing photocatalysts with optimized activity through expanding the light absorption range [8,9], improving the photocarrier separation efficiency [10,11] and tuning the active sites distribution [12-14]. Among versatile semiconductor photocatalysts, $\mathrm{TiO}_{2}$ has received the most attention benefitting from the excellent physicochemical stability $[12,15]$, nontoxicity $[9,16,17]$, and suitable redox potentials $[18,19]$. In view of the importance of $\mathrm{TiO}_{2}$, it is not surprising that various approaches for the structure-tuning of $\mathrm{TiO}_{2}$ have been reported, and the structure-tuning still remains a particularly active research field [20-23].

Currently, the restriction to the application of $\mathrm{TiO}_{2}$ is mainly caused by the poor light absorption and inefficient electron-hole separation [24-28]. The single crystal is expected to facilitate the separation and transportation of photo-generated charge carrier due to the fewer crystal boundaries [29-32]. Since the report by Yang et al about the preparation of single crystal anatase $\mathrm{TiO}_{2}$ with co-exposed (001) and (101) facets [33], great attention has been focused on synthesizing single crystal semiconductors and modulating its photo-physicochemical performance. Meanwhile, to promote the transportation of photo-carrier to the surface, porous 
single crystal is fabricated using nanometer-sized $\mathrm{SiO}_{2}$ microarray as the porogen [34]. However, compared with the facets tuning [23, 35-37], there are fewer studies about the tuning of the porous properties, which may be ascribed to the contradiction between orientated growth of single crystal and rigidity of the hard template. Considering more tunable photocatalytic performance of polycrystallite as a benefit of versatile porous and cavitary structures [38-41], it is desired to further develop strategies for flexible porosity tuning of single crystal structure, thus providing more opportunities for engineering the light-matter interaction. Herein, hierarchical macro-mesoporous anatase single crystal is templated from partly glassified polystyrene sphere using $\mathrm{TiF}_{4}$ as the precursor. Partly glassified PS during the hydrolysis condensation of $\mathrm{TiF}_{4}$ is essential for the formation of hierarchical porosity. Macropores with an average diameter of 100 $\mathrm{nm}$ and mesopores with an average diameter of $30 \mathrm{~nm}$ are formed through the glassfication and calcination of PS. The hierarchical porous structure provides accessible inner active sites and more surface defects to reactants, which present sound activity towards organics degradation.

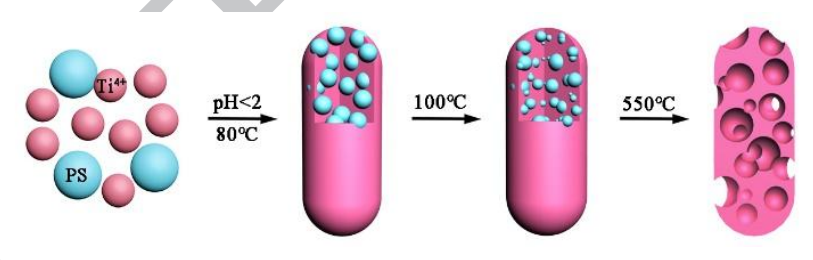

Scheme 1. Synthesis processes of porous $\mathrm{TiO}_{2}$ using partly glassified PS as the template.

As illustrated in Scheme 1, PS (ca. 200 nm, Fig. S1) is directly mixed with $\mathrm{TiF}_{4}$, which are well miscible since the sulfate on PS can coordinate with titanium. The sulfate on PS is resulted from the potassium persulfate as the initiator for the polymerization of styrene. The subsequent hydrolytic condensation of $\mathrm{TiF}_{4}$ at $100{ }^{\circ} \mathrm{C}$ leads to the encapsulation of PS inside titania due to the good miscibility, and PS is gradually glassified. Since PS is partly glassified and elastic, the interference to the orientation growth of single crystal by hard template is supposed to be 
minimized. The hydrolytic condensation of $\mathrm{TiF}_{4}$ is carried out at $100{ }^{\circ} \mathrm{C}$ only for 30 mins to prevent the complete glassification of PS. The reaction temperature is then decreased to $80{ }^{\circ} \mathrm{C}$ and the solution is stirred for $12 \mathrm{~h}$. After centrifugation and drying, the as-obtained white powder is then calcined at $550{ }^{\circ} \mathrm{C}$ in air for $2 \mathrm{~h}$ to remove PS.

The rod-like PS- $\mathrm{TiO}_{2}$ is monodispersed with a uniform size of ca. $520 \mathrm{~nm}$ in length and 200 nm in width (Fig. 1a). As seen from TEM (Fig. 1b) and FESEM (Fig. 1c) image, porous $\mathrm{TiO}_{2}$ has macropores (ca. $100 \mathrm{~nm}$ ) and mesopores (ca. $30 \mathrm{~nm}$ ). It is supposed that the mesopores are mainly generated from the glassified PS fraction. HRTEM image taken from the edge of the lateral of the rod indicates three sets of lattice fringes with spacings of $0.35 \mathrm{~nm}, 0.35 \mathrm{~nm}$, and $0.48 \mathrm{~nm}$, which correspond to the $\{101\},\{10 \overline{1}\}$ and $\{00 \overline{2}\}$ crystallographic planes of anatase $\mathrm{TiO}_{2}$. The electron diffraction pattern indicates that such prepared material is single crystal (inset of Fig. 1d). In contrast, the dip-coating of $\mathrm{TiF}_{4}$ into PS microarray at room temperature followed by calcination leads to the formation of porous $\mathrm{TiO}_{2}$ polycrystalline (Fig. S2, 3), suggesting the interference from the hard template on the oriental growth of single crystal is minimized through using partly glassified PS. Naturally, anatase $\mathrm{TiO}_{2}$ is a truncated octahedral bipyramid comprising of eight $\{101\}$ facets on sides and two $\{001\}$ facets on the top and bottom. Here, the adjacent cavities grown along the rods show hexagon-like shape and the angle between top and side is ca. $68.3^{\circ}$, which is accordant with the interfacial angle between (001) and (101) facets of anatase $\mathrm{TiO}_{2}$ single crystal $[42,43]$. During the condensation of the titanates, the glassified PS provides sufficient deformability to the growth of the single crystal. Meanwhile, the adjacent PS leads to the growth of single crystal along [001] axis. The influence of the temperature on the assembly of PS and titania species is investigated to understand the formation mechanism. Mesoporous nanorods with a length of ca. $200 \mathrm{~nm}$ are formed when the temperature increases to $120{ }^{\circ} \mathrm{C}$ (Fig. S4). A higher temperature of $180{ }^{\circ} \mathrm{C}$ leads to the formation of bulk particles without 
obvious porous structure (Fig. S5). The failure to the formation of macropore at $120{ }^{\circ} \mathrm{C}$ and porosity at $180{ }^{\circ} \mathrm{C}$ should be attributed to the over glassification of PS, leading to the inefficient interaction between PS and titania during the hydrolytic condensation step. Based on the above results, it is supposed that the rod-like structure is resulted from the stacking growth of PSembedded $\mathrm{TiO}_{2}$ single crystal nanoparticles along [001] axis, which is co-exposed with $\{001\}$ and $\{101\}$ facets. The macroporous and mesoporous are templated from un-glassified PS and its glassified fraction, respectively. However, when the heating temperature does not reach $100{ }^{\circ} \mathrm{C}$, no apparent glassification of PS can be observed (Fig. S6), and polymorph $\mathrm{TiO}_{2}$ are formed according to the selected-area electron diffraction pattern (Fig. S7). Several other control samples are also prepared using isopropyl titanate as the titanium source (Fig. S8), $\mathrm{SiO}_{2}$ as templates (Fig. S9), or without adding PS templates (Fig. S10), and no single crystal structure can be obtained.

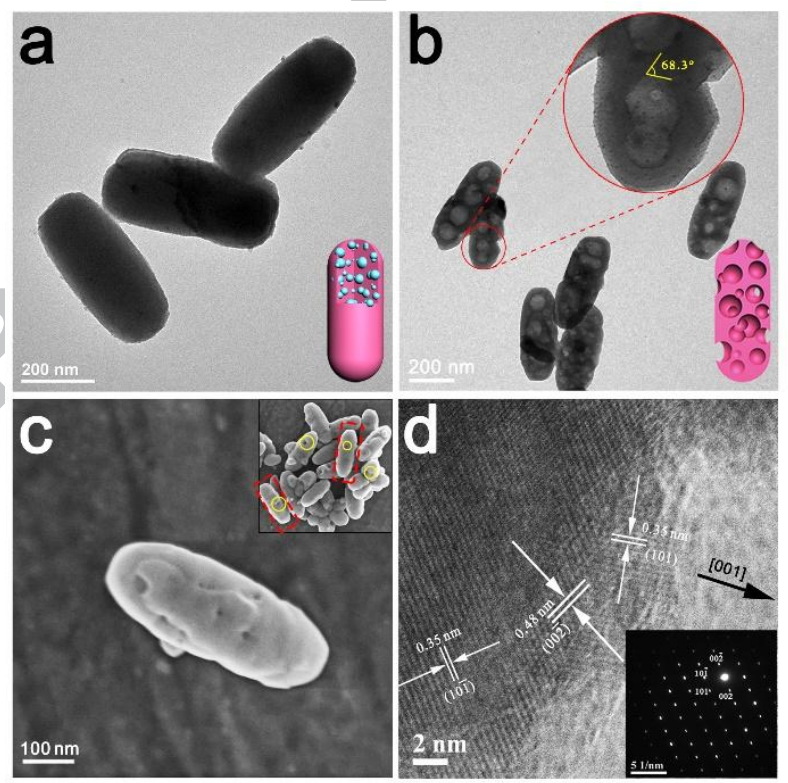

Figure 1. TEM images of $\mathrm{PS}-\mathrm{TiO}_{2}$ and porous $\mathrm{TiO}_{2}(\mathrm{a}, \mathrm{b})$, FESEM image of porous $\mathrm{TiO}_{2}(\mathrm{c})$, HRTEM and SAD images (inset) of porous $\mathrm{TiO}_{2}(\mathrm{~d})$. 
The characteristic XRD pattern of hierarchical porous $\mathrm{TiO}_{2}$ single crystal encompass diffraction peaks at $25.3^{\circ}(101), 37.8^{\circ}(004), 48.1^{\circ}(200), 53.9^{\circ}(105)$ and $62.7^{\circ}(204)$, which can be assigned to the crystalline anatase phase of $\mathrm{TiO}_{2}$ (tetragonal, I4/amd, JCPDS 21-1272, Fig. 2a), demonstrating the pure anatase $\mathrm{TiO}_{2}$ phase. The Raman spectrum exhibits vibration modes at 144.0, 197, 397, 514 and $638 \mathrm{~cm}^{-1}$ (Fig. 2b), which are indexed to $E_{g(1)}, E_{g(2)}, B_{1 g(1)}, A_{1 g}$ and $\mathrm{E}_{\mathrm{g}(3)}$ vibration modes of anatase phase [44], further verifying the existence of anatase phase. The symmetric and intensive $\mathrm{E}_{\mathrm{g}}$ peak at $144 \mathrm{~cm}^{-1}$ corresponding to the phonon mode of anatase $\mathrm{E}_{\mathrm{g}(1)}$ demonstrates the high crystallinity of porous single crystal. The $\mathrm{N}_{2}$ sorption isotherm shows a type II curve characteristic of a distinguishable multilayer adsorption step in the high relative pressure area $\left(\mathrm{P} / \mathrm{P}_{0}\right)$ above 0.8 (Fig. 2c). The pore size distribution calculated by the BarrettJoyner-Halenda (BJH) model (inset of Fig. 2c) is ca. $30 \mathrm{~nm}$, which is in accordant with the result from TEM image (Fig. 1b). The Brunner-Emmet-Teller (BET) specific surface area and pore volume are calculated to be $25.8 \mathrm{~m}^{2} \mathrm{~g}^{-1}$ and $0.135 \mathrm{~cm}^{3} \mathrm{~g}^{-1}$. X-ray photoelectron spectroscopy (XPS) analysis is performed to determine the surface chemical composition (Fig. 2d). Three characteristic peaks of $\mathrm{Ti}, \mathrm{O}$ and $\mathrm{C}$ are observed from the survey XPS spectrum, indicating the complete removal of $\mathrm{F}$. The carbon peak is attributed to the adventitious hydrocarbon from the XPS instrument itself. 

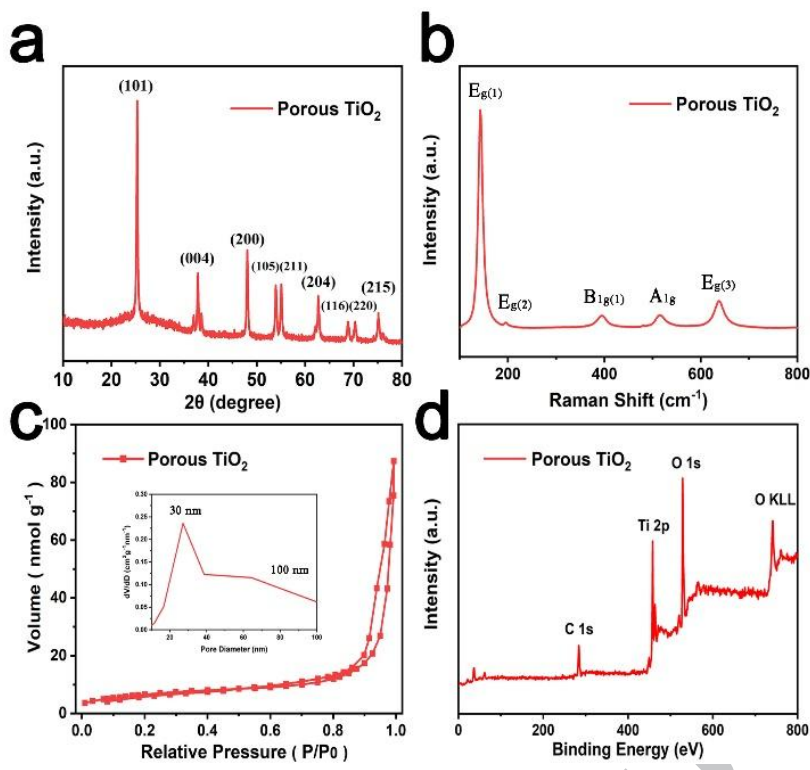

Figure 2. XRD pattern (a), Raman spectrum (b), $\mathrm{N}_{2}$ sorption isotherm (c), and XPS spectrum (d) of porous $\mathrm{TiO}_{2}$. Inset is the average pore-size distribution.

XPS is also a unique tool to investigate surface defects and chemical environment because of its high surface sensitivity. Evidence of oxygen vacancy are further revealed from the O 1s spectrum of porous single crystal (Fig. 3a), which exhibits an asymmetric curve and a broad shoulder in the higher binding energy side. The intense peak at about $529.2 \mathrm{eV}$ is attributed to $\mathrm{O}$ in the $\mathrm{TiO}_{2}$ crystal lattice, while the shoulder peaks centered at $531.4 \mathrm{eV}$ can be assigned to the

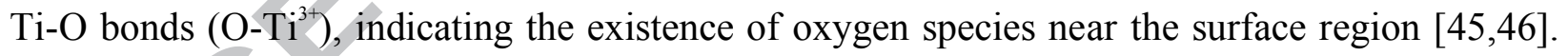
Compared with nonporous sample, the intensity of ${\mathrm{O}-\mathrm{Ti}^{3+}}^{3}$ increases due to the existence of porous structure, suggesting the dramatic increase of the oxygen defects concentration. Specifically, the atomic ratio of oxygen vacancy in hierarchical porous $\mathrm{TiO}_{2}$ is roughly calculated to be $15.9 \%$, while that in nonporous $\mathrm{TiO}_{2}$ is just $6.7 \%$ (Fig. S12). According to the UV-Vis spectrum (Fig. 3b), the porous single crystal has an absorption band centered at $325 \mathrm{~nm}$. Photoluminescne (PL) is further used to reveal the nature of defects, which are measured at room temperature using an excitation wavelength of $325 \mathrm{~nm}$. The visible PL is known to be attributed 
to the presence of oxygen vacancies (Vo) since the band transition $\mathrm{PL}$ of $\mathrm{TiO}_{2}$ locates at ca. 380 nm (not shown). As seen from Fig. 3c, the broad visible PL is primarily related to self-trapped excitons and oxygen vacancy related defect states. The spectrum is further deconvoluted into three Gaussian bands centred at 457, 489 and $541 \mathrm{~nm}$ [47]. The first peak may be ascribed to the self-trapped excitons located at $\mathrm{TiO}_{6}$ octahedra, while the other two peaks are ascribed to Vorelated trap states. The PL emission is enhanced enormously in porous single crystal compared with other three samples (Fig. S13), strongly indicating that concentration of oxygen vacancies is dramatically improved in porous single crystal. To ensure the category and quantity of the surface defects, EPR spectrometer is adopted to investigate the related surface defects $[48,49]$. EPR is the resonant absorption of microwave radiation by paramagnetic systems in the presence of an applied magnetic field. The g value is calculated from the equation:

$$
g=\frac{h v}{\beta H}
$$

In the equation, $\mathrm{g}$ is the $\mathrm{g}$-factor, $\mathrm{h}$ is the Planck's constant $\left(6.626^{*} 10^{-27} \mathrm{erg} \cdot \mathrm{s}\right), v$ is the microwave frequency $(9.90 \mathrm{GHz}), \beta$ is the Bohr magneton $\left(9.274^{*} 10^{-21} \mathrm{erg} \cdot \mathrm{G}^{-1}\right)$, and $\mathrm{H}$ is the magnetic field strength. It can be observed that there is a main resonance line located at a magnetic field strength of $3560 \mathrm{G}$ (Fig. 4d), which corresponds to the g-factor around 1.99 and is attributed to $\mathrm{Ti}^{3+}$ in anatase phase. The quantity of $\mathrm{Ti}^{3+}$ is demonstrated by the EPR intensity of each sample, and the porous $\mathrm{TiO}_{2}$ has the highest concentration ratio of $\mathrm{Ti}^{3+}$. Furthermore, in the EPR curve of porous $\mathrm{TiO}_{2}$, resonance line which locates at $3525 \mathrm{G}$ corresponds to the g-factor of 2.003. Such signal can be ascribed to the Vo while there are no signals of Vo in nonporous $\mathrm{TiO}_{2}$, bulk $\mathrm{TiO}_{2}$ or $\mathrm{IO} \mathrm{TiO}_{2}$. 

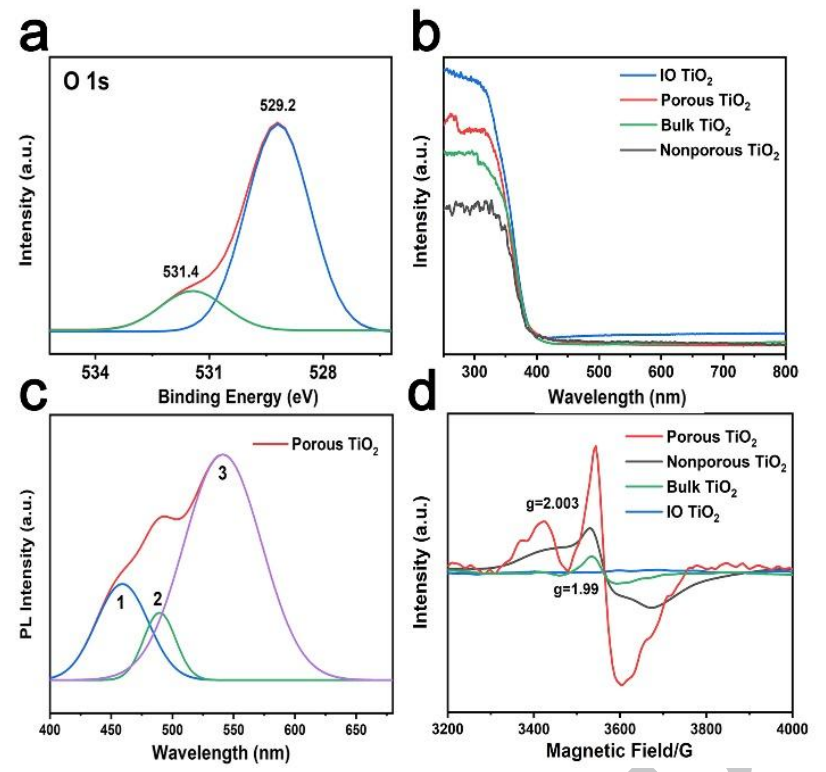

Figure 3. O 1s XPS, UV-Vis absorption, PL, and EPR spectra of porous $\mathrm{TiO}_{2}$ (a-d).

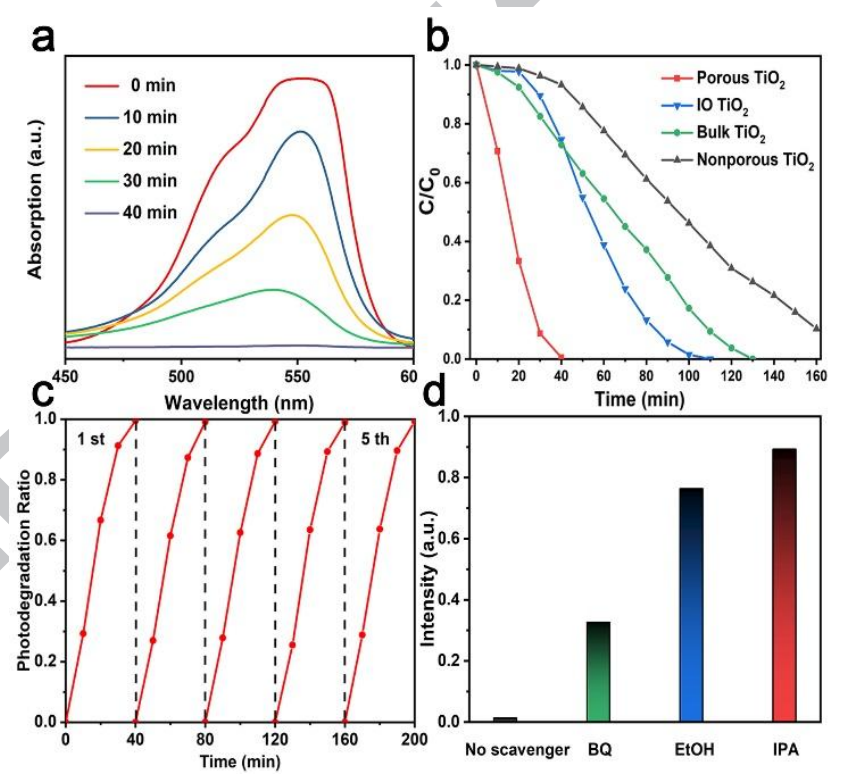

Figure 4. UV-Vis absorption spectra of $\mathrm{RhB}(20 \mathrm{mg} / \mathrm{L})$ irradiated in the presence of porous $\mathrm{TiO}_{2}$ and collected at a 10-minute interval (a), degradation curves of $\mathrm{RhB}$ by different $\mathrm{TiO}_{2}$ samples (b), cycling performance of porous $\mathrm{TiO}_{2}$ (c) and degradation efficiency of $\mathrm{RhB}$ by porous $\mathrm{TiO}_{2}$ in the presence of different capture agents (d). 
Photocatalytic experiments were carried out under simulated sunlight irradiation (300 W) using Rhodamine $B(\mathrm{RhB})$ as the model molecule. As shown in Fig. 4a, $\mathrm{RhB}\left(20 \mathrm{mg} \mathrm{L}^{-1}\right)$ is completely degraded within 40 mins using hierarchical porous $\mathrm{TiO}_{2}$ single crystal as the catalyst, which is almost four times faster than nonporous $\mathrm{TiO}_{2}$ and three times faster than bulk $\mathrm{TiO}_{2}$ and IO $\mathrm{TiO}_{2}$ (Fig. 4b). No obvious contribution from the adsorption can be observed. Moreover, after being recycled for five times, the degradation efficiency of porous single crystal shows negligible decline (Fig. 4c), which testifies the high stability and reproducibility of the catalyst. MB (20 mg L $\left.\mathrm{m}^{-1}\right)$ and MO (15 $\left.\mathrm{mg} \mathrm{L}^{-1}\right)$ solutions are also degraded under the same condition by hierarchical porous $\mathrm{TiO}_{2}$ single crystal to check its universality for the degradation of organic dyes. As shown in Fig. S14 and Fig. S15, hierarchical porous $\mathrm{TiO}_{2}$ single crystal displays excellent photoactivity in decomposing both $\mathrm{MB}$ and $\mathrm{MO}$, when compared with other three common $\mathrm{TiO}_{2}$ materials. $\mathrm{MB}\left(20 \mathrm{mg} \mathrm{L}^{-1}\right)$ and $\mathrm{MO}\left(15 \mathrm{mg} \mathrm{L}^{-1}\right)$ can be degraded completely within 30 mins and 40 mins respectively. In order to reveal the active species, the photocatalytic activity was evaluated for the degradation of $\mathrm{RhB}$ in the presence of different radical captures. The substances employed in this work are iso-propanol for hydroxyl radical scavenging, ethanol for hole-trapping scavenging, and 1, 4-benzoquinone as a scavenger for superoxide radicals. Propanol is known to be a good scavenger for hydroxyl radicals due to its high rate constant of reaction with the radical $\left(1.9 \times 10^{9} \mathrm{~m}^{-1} \mathrm{~s}^{-1}\right)$. The results of the active species detection are showed in Fig. 4d. Photocatalytic degradation efficiency of $\mathrm{RhB}$ via porous $\mathrm{TiO}_{2}$ is greatly depressed when either IPA or EtOH is added into the system, and the removal ratio of $\mathrm{RhB}$ also decreases a little in the presence of BQ. Based on the above results, $\bullet \mathrm{OH}$ and $\mathrm{h}^{+}$are determined as the main reactive species for $\mathrm{RhB}$ degradation in this research and $\bullet \mathrm{O}_{2}{ }^{-}$does not have a significant effect on the degradation of RhB. 


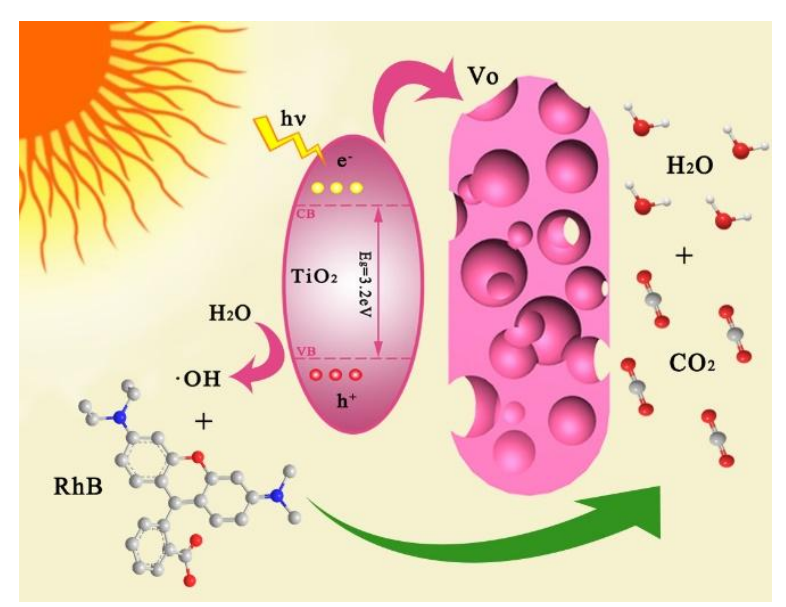

Scheme 2. Mechanism diagram for RhB degradation.

To understand the mechanism for the improved photocatalytic activity, photocurrent analysis was then conducted. As shown in Fig. 5a, porous $\mathrm{TiO}_{2}$ single crystal can generate the highest photocurrent which is as twice as the photocurrent generated by $\mathrm{IO}^{\mathrm{TiO}_{2}}$ and over 10 times by bulk $\mathrm{TiO}_{2}$ and nonporous $\mathrm{TiO}_{2}$. Electrochemical impedance measurements (EIS) were further carried out to elucidate the correlation between porous structures and the enhanced photocurrents. Fig. $5 \mathrm{~b}$ shows the impedance spectra of four samples including porous $\mathrm{TiO}_{2}$, nonporous $\mathrm{TiO}_{2}, \mathrm{IO}$ $\mathrm{TiO}_{2}$ and bulk $\mathrm{TiO}_{2}$ measured under simulated sunlight irradiation. Larger arches can be observed from nonporous $\mathrm{TiO}_{2}, \mathrm{IO} \mathrm{TiO}_{2}$ and bulk $\mathrm{TiO}_{2}$ than that from porous $\mathrm{TiO}_{2}$ single crystals, demonstrating reduced charge transfer resistance in porous single crystal. Small values of charge transfer resistance suggest fast charge transport properties due to reduced recombination rates of electron-hole pairs in porous $\mathrm{TiO}_{2}$. Moreover, porous $\mathrm{TiO}_{2}$ single crystal also presents the smallest impedance when measured in dark (Fig. S16), which is further decreased after being illuminated with the light, further verifying the improved carrier transportaion in porous single crystal. Mott-Schottky plots are generated based on the capacitances derived from the electrochemical impedance (Fig. 5c), from which flat band potential $\left(\mathrm{V}_{\mathrm{fb}}\right)$ and donor density can be calculated [33]. The $\mathrm{V}_{\mathrm{fb}}$ of porous $\mathrm{TiO}_{2}$, nonporous $\mathrm{TiO}_{2}, \mathrm{IO} \mathrm{TiO}_{2}$ and bulk $\mathrm{TiO}_{2}$ are 
determined to be $-0.31 \mathrm{~V},-0.37 \mathrm{~V},-0.42 \mathrm{~V}$ and $-0.45 \mathrm{~V}$ vs RHE. Compared with the bulk counterpart, positive shift of $\mathrm{V}_{\mathrm{fb}}$ for porous $\mathrm{TiO}_{2}$ demonstrates the decrease of band bending. This decrease of band edge bending can be attributed to the increased contact between porous electrode and the electrolyte $[50,51]$, which can efficiently facilitate the charge transfer. The flat band shift also has a major effect on the enhanced photocurrent for porous $\mathrm{TiO}_{2}$. The donor density can be calculated according to the following equation:

$$
\mathrm{N}_{\mathrm{d}}=\left(2 / \mathrm{e} \varepsilon_{\mathrm{p}}\right)\left[\mathrm{d}\left(1 / \mathrm{C}^{2}\right) / \mathrm{dV}\right]^{-1}
$$

where e is the electron charge, $\varepsilon$ is the dielectric constant of hematite, $\varepsilon_{0}$ is the permittivity of vacuum, $\mathrm{N}_{\mathrm{d}}$ is the dopant density, and $\mathrm{C}$ is the capacitance derived from the electrochemical impedance obtained at each potential (V) with $3000 \mathrm{~Hz}$ frequency. With an $\varepsilon$ value of 48 for anatase, the donor density of porous $\mathrm{TiO}_{2}$ is calculated to be $6.5 \times 10^{18}$, which is nearly twice of the nonporous one $\left(3.2 \times 10^{18}\right)$. These results indicate that the porous structure of $\mathrm{TiO}_{2}$ single crystal provides more channels for electron transportation. According to the above results, the possible mechanism for improved photocatalytic activity of porous single crystal is then proposed in Scheme 2. The single crystal has improved carrier transportation ability due to the fewer crystalline boundaries. Meanwhile, as there are numerous macro- and mesopores in porous single crystal $\mathrm{TiO}_{2}$, abundant Vo are formed after the PS removal through calcination, which significantly retards the combination of holes and electrons. The photo-generated holes can efficiently transport to the surface and react with $\mathrm{H}_{2} \mathrm{O}$ or surface $-\mathrm{OH}$ to form highly active hydroxyl radicals $(\bullet \mathrm{OH})$, which then oxidize organic pollutants to nontoxic small molecules. 

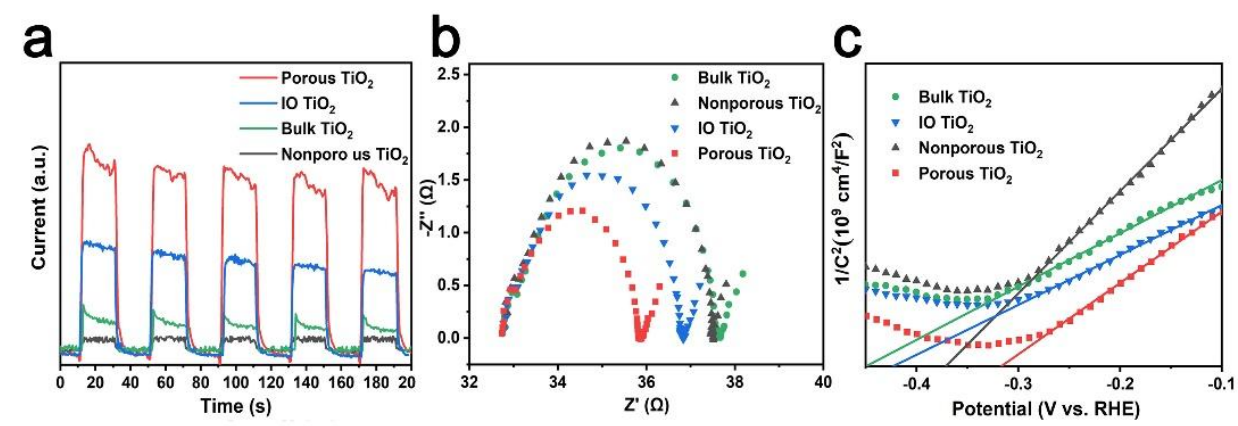

Figure 5. Photocurrent curve (a), EIS spectra (b), and Mott Schottky curve (c) of four contrast samples.

In conclusion, hierarchical macro-mesoporous $\mathrm{TiO}_{2}$ single crystals have been synthesized using partly glassified PS as the single hard template. The as-prepared porous $\mathrm{TiO}_{2}$ is characteristic of good crystallinity, low mass density and abundant surface oxygen vacancies. When applied in the degradation of organics, this porous $\mathrm{TiO}_{2}$ single crystal exhibits excellent photocatalytic activity and sound photo-physicochemical stability. A photocatalytic mechanism based on the cooperation of facilitated charge transportation on single crystal and retard holeelectron recombination by oxygen yacancies is validated through multiple characterizations. It is expected that this one-pot hard-template strategy to hierarchical porous single crystal can be further applied in the fabrication of other components in considering the simple and flexible process.

The authors declare no competing financial interest.

\section{Acknowledgement}

This work is sponsored by the National Natural Science Foundation of China (21673073, 21677048, 5171101651 and U1407102), the Science and Technology Commission of Shanghai Municipality (18520710200, 16JC1401400, 17520711500), Shanghai Pujiang Program 
(18PJD012), PetroChina Innovation Foundation (2015D-5006-0402) and the Fundamental

Research Funds for the Central Universities (222201717003, 22221818014).

References

[1] J.A. Byrne, B.R. Eggins, N.M.D. Brown, B. McKinney, M. Rouse, Immobilisation of $\mathrm{TiO}_{2}$ powder for the treatment of polluted water, Appl. Catal. B Environ. 17 (1998) 2536.

[2] Y.H. Hsien, C.F. Chang, Y.H. Chen, S. Cheng, Photodegradation of aromatic pollutants in water over $\mathrm{TiO}_{2}$ supported on molecular sieves, Appl. Catal. B Environ. 31 (2001) 241249.

[3] S.H.I. Keyu, C. Bais, Y. Kelian, H.E. Shangjin, Preparation and Characterization of Porous Microspheres Composed of $\mathrm{TiO}_{2}$ Nanocrystals, 40 (2002) 2-5.

[4] J. Low, B. Cheng, J. Yu, Surface modification and enhanced photocatalytic $\mathrm{CO}_{2}$ reduction performance of $\mathrm{TiO}_{2}$ : a review, Appl. Surf. Sci. 392 (2017) 658-686.

[5] K. Hashimoto, H. Irie, A. Fujishima, $\mathrm{TiO}_{2}$ Photocatalysis: A Historical Overview and Future Prospects, Jpn. J. Appl. Phys. 44 (2005) 8269-8285.

[6] I.K. Konstantinou, T.A. Albanis, $\mathrm{TiO}_{2}$-assisted photocatalytic degradation of azo dyes in aqueous solution: Kinetic and mechanistic investigations: A review, Appl. Catal. B Environ. 49 (2004) 1-14.

[7] A. Fujishima, X. Zhang, D.A. Tryk, $\mathrm{TiO}_{2}$ photocatalysis and related surface phenomena, Surf. Sci. Rep. 63 (2008) 515-582.

[8] Y. Yang, L.C. Yin, Y. Gong, P. Niu, J.Q. Wang, L. Gu, X. Chen, G. Liu, L. Wang, H.M. Cheng, An Unusual Strong Visible-Light Absorption Band in Red Anatase $\mathrm{TiO}_{2}$ Photocatalyst Induced by Atomic Hydrogen-Occupied Oxygen Vacancies, Adv. Mater. 30 (2018) 1-8. 
[9] Y. Yang, Q. Jin, D. Mao, J. Qi, Y. Wei, R. Yu, A. Li, S. Li, H. Zhao, Y. Ma, L. Wang, W. $\mathrm{Hu}$, D. Wang, Dually Ordered Porous $\mathrm{TiO}_{2}-\mathrm{rGO}$ Composites with Controllable Light Absorption Properties for Efficient Solar Energy Conversion, Adv. Mater. 29 (2017) 1-7.

[10] X. Liu, G. Dong, S. Li, G. Lu, Y. Bi, Direct Observation of Charge Separation on Anatase $\mathrm{TiO}_{2}$ Crystals with Selectively Etched $\{001\}$ Facets, J. Am. Chem. Soc. 138 (2016) 29172920.

[11] X. Cheng, S. Ding, J. Guo, C. Zhang, Z. Guo, L. Shao, In-situ interfacial formation of $\mathrm{TiO}_{2}$ /polypyrrole selective layer for improving the separation efficiency towards molecular separation, J. Memb. Sci. 536 (2017) 19-27.

[12] T. Fujitani, I. Nakamura, Mechanism and active sites of the oxidation of CO over $\mathrm{Au} / \mathrm{TiO}_{2}$, Angew. Chemie-Int. Ed. 50 (2011) 10144-10147.

[13] M. Pelaez, N.T. Nolan, S.C. Pillai, M.K. Seery, P. Falaras, A.G. Kontos, P.S.M. Dunlop, J.W.J. Hamilton, J.A. Byrne, K. O’Shea, M.H. Entezari, D.D. Dionysiou, A review on the visible light active titanium dioxide photocatalysts for environmental applications, Appl. Catal. B Environ. 125 (2012) 331-349.

[14] Y. Cong, B. Tian, J. Zhang, Improving the thermal stability and photocatalytic activity of nanosized titanium dioxide via $\mathrm{La}^{3+}$ and $\mathrm{N}$ co-doping, Appl. Catal. B Environ. 101 (2011) $376-381$.

[15] H. Choi, E. Stathatos, D.D. Dionysiou, Sol-gel preparation of mesoporous photocatalytic TiO2films and $\mathrm{TiO}_{2} / \mathrm{Al}_{2} \mathrm{O}_{3}$ composite membranes for environmental applications, Appl. Catal. B Environ. 63 (2006) 60-67.

[16] Y. Zhao, C. Li, X. Liu, F. Gu, H.L. Du, L. Shi, Zn-doped $\mathrm{TiO}_{2}$ nanoparticles with high photocatalytic activity synthesized by hydrogen-oxygen diffusion flame, Appl. Catal. B Environ. 79 (2008) 208-215.

[17] C. Lettmann, K. Hildenbrand, H. Kisch, W. Macyk, W.F. Maier, Visible light photodegradation of 4-chlorophenol with a coke-containing titanium dioxide photocatalyst, Appl. Catal. B Environ. 32 (2001) 215-227. 
[18] G.M. Carroll, C.K. Brozek, K.H. Hartstein, E.Y. Tsui, D.R. Gamelin, Potentiometric Measurements of Semiconductor Nanocrystal Redox Potentials, J. Am. Chem. Soc. 138 (2016) 4310-4313.

[19] Q. Kang, T. Wang, P. Li, L. Liu, K. Chang, M. Li, J. Ye, Photocatalytic Reduction of Carbon Dioxide by Hydrous Hydrazine over $\mathrm{Au}-\mathrm{Cu}$ Alloy Nanoparticles Supported on $\mathrm{SrTiO}_{3} / \mathrm{TiO}_{2}$ Coaxial Nanotube Arrays, Angew. Chemie Int. Ed. 54 (2015) 841-845.

[20] Y. Wang, W. Yang, X. Chen, J. Wang, Y. Zhu, Photocatalytic activity enhancement of core-shell structure g- $\mathrm{C}_{3} \mathrm{~N}_{4} @ \mathrm{TiO}_{2}$ via controlled ultrathin g- $\mathrm{C}_{3} \mathrm{~N}_{4}$ layer, Appl. Catal. B Environ. 220 (2018) 337-347.

[21] K.R. Reddy, M. Hassan, V.G. Gomes, Hybrid nanostructures based on titanium dioxide for enhanced photocatalysis, Appl. Catal. A Gen. 489 (2015) 1-16.

[22] A. Cybula, J.B. Priebe, M.M. Pohl, J.W. Sobczak, M. Schneider, A. Zielińska-Jurek, A. Brückner, A. Zaleska, The effect of calcination temperature on structure and photocatalytic properties of $\mathrm{Au} / \mathrm{Pd}$ nanoparticles supported on $\mathrm{TiO}_{2}$, Appl. Catal. B Environ. 152-153 (2014) 202-211.

[23] Z. Huang, Q. Sun, K. Lv, Z. Zhang, M. Li, B. Li, Effect of contact interface between $\mathrm{TiO}_{2}$ and $\mathrm{g}-\mathrm{C}_{3} \mathrm{~N}_{4}$ on the photoreactivity of $\mathrm{g}-\mathrm{C}_{3} \mathrm{~N}_{4} / \mathrm{TiO}_{2}$ photocatalyst: (001) vs (101) facets of $\mathrm{TiO}_{2}$, Appl. Catal. B Environ. 164 (2015) 420-427.

[24] J. Zhang, Z. Yu, Z. Gao, H. Ge, S. Zhao, C. Chen, S. Chen, X. Tong, M. Wang, Z. Zheng, Y. Qin, Porous $\mathrm{TiO}_{2}$ Nanotubes with Spatially Separated Platinum and $\mathrm{CoO}_{\mathrm{x}}$ Cocatalysts Produced by Atomic Layer Deposition for Photocatalytic Hydrogen Production, Angew. Chemie Int. Ed. 56 (2017) 816-820.

[25] M. Minella, F. Sordello, C. Minero, Photocatalytic process in $\mathrm{TiO}_{2} /$ graphene hybrid materials. Evidence of charge separation by electron transfer from reduced graphene oxide to $\mathrm{TiO}_{2}$, Catal. Today. 281 (2017) 29-37. 
[26] X. Liu, Z. Xing, H. Zhang, W. Wang, Y. Zhang, Z. Li, X. Wu, X. Yu, W. Zhou, Fabrication of 3D Mesoporous Black $\mathrm{TiO}_{2} / \mathrm{MoS}_{2} / \mathrm{TiO}_{2}$ Nanosheets for Visible-LightDriven Photocatalysis, ChemSusChem. 9 (2016) 1118-1124.

[27] Y. Dou, S. Zhang, T. Pan, S. Xu, A. Zhou, M. Pu, H. Yan, J. Han, M. Wei, D.G. Evans, X. Duan, $\mathrm{TiO}_{2} @$ layered double hydroxide core-shell nanospheres with largely enhanced photocatalytic activity toward $\mathrm{O}_{2}$ generation, Adv. Funct. Mater. 25 (2015) 2243-2249.

[28] J. Lim, D. yeob Kwak, F. Sieland, C. Kim, D.W. Bahnemann, W. Choi, Visible lightinduced catalytic activation of peroxymonosulfate using heterogeneous surface complexes of amino acids on $\mathrm{TiO}_{2}$, Elsevier B.V., 2018.

[29] Z. Le, F. Liu, P. Nie, X. Li, X. Liu, Z. Bian, G. Chen, H. Bin Wu, Y. Lu, Pseudocapacitive Sodium Storage in Mesoporous Single-Crystal-like $\mathrm{TiO}_{2}$-Graphene Nanocomposite Enables High-Performance Sodium-Ion Capacitors, ACS Nano. 11 (2017) 2952-2960.

[30] J. Shao, W. Sheng, M. Wang, S. Li, J. Chen, Y. Zhang, S. Cao, In situ synthesis of carbondoped $\mathrm{TiO}_{2}$ single-crystal nanorods with a remarkably photocatalytic efficiency, Appl. Catal. B Environ. 209 (2017) 311-319.

[31] K. Ozawa, M. Emori, S. Yamamoto, R. Yukawa, S. Yamamoto, R. Hobara, K. Fujikawa, H. Sakama, I. Matsuda, Electron-hole recombination time at $\mathrm{TiO}_{2}$ single-crystal surfaces: Influence of surface band bending, J. Phys. Chem. Lett. 5 (2014) 1953-1957.

[32] J. Li, K. Cao, Q. Li, D. Xu, Tetragonal faceted-nanorods of anatase $\mathrm{TiO}_{2}$ with a large percentage of active $\{100\}$ facets and their hierarchical structure, CrystEngComm. 14 (2012) 83-85.

[33] H.G. Yang, C.H. Sun, S.Z. Qiao, J. Zou, G. Liu, S.C. Smith, H.M. Cheng, G.Q. Lu, Anatase $\mathrm{TiO}_{2}$ single crystals with a large percentage of reactive facets, Nature. 453 (2008) 638-641.

[34] E.J.W. Crossland, N. Noel, V. Sivaram, T. Leijtens, J.A. Alexander-Webber, H.J. Snaith, Mesoporous $\mathrm{TiO}_{2}$ single crystals delivering enhanced mobility and optoelectronic device performance, Nature. 495 (2013) 215-219. 
[35] Q. Xiang, K. Lv, J. Yu, Pivotal role of fluorine in enhanced photocatalytic activity of anatase $\mathrm{TiO}_{2}$ nanosheets with dominant (001) facets for the photocatalytic degradation of acetone in air, Appl. Catal. B Environ. 96 (2010) 557-564.

[36] J. Yu, J. Low, W. Xiao, P. Zhou, M. Jaroniec, Enhanced Photocatalytic $\mathrm{CO}_{2}$-Reduction Activity of Anatase $\mathrm{TiO}_{2}$ by, 3 (2014).

[37] S. Liu, J. Yu, M. Jaroniec, Tunable photocatalytic selectivity of hollow $\mathrm{TiO}_{2}$ microspheres composed of anatase polyhedra with exposed $\{001\}$ facets, J. Am. Chem. Soc. 132 (2010) 11914-11916.

[38] W. Ren, Z. Ai, F. Jia, L. Zhang, X. Fan, Z. Zou, Low temperature preparation and visible light photocatalytic activity of mesoporous carbon-doped crystalline $\mathrm{TiO}_{2}$, Appl. Catal. B Environ. 69 (2007) 138-144.

[39] F. Iskandar, A.B.D. Nandiyanto, K.M. Yun, C.J. Hogan, K. Okuyama, P. Biswas, Enhanced photocatalytic performance of brookite $\mathrm{TiO}_{2}$ macroporous particles prepared by spray drying with colloidal templating, Adv. Mater. 19 (2007) 1408-1412.

[40] J. Yu, G. Wang, B. Cheng, M. Zhou, Effects of hydrothermal temperature and time on the photocatalytic activity and microstructures of bimodal mesoporous $\mathrm{TiO}_{2}$ powders, Appl. Catal. B Environ. 69 (2007) 171-180.

[41] N. Arconada, A. Durán, S. Suárez, R. Portela, J.M. Coronado, B. Sánchez, Y. Castro, Synthesis and photocatalytic properties of dense and porous $\mathrm{TiO}_{2}$-anatase thin films prepared by sol-gel, Appl. Catal. B Environ. 86 (2009) 1-7.

[42] L. Ye, J. Mao, J. Liu, Z. Jiang, T. Peng, L. Zan, Synthesis of anatase $\mathrm{TiO}_{2}$ nanocrystals with $\{101\},\{001\}$ or $\{010\}$ single facets of $90 \%$ level exposure and liquid-phase photocatalytic reduction and oxidation activity orders, J. Mater. Chem. A. 1 (2013) $10532-10537$.

[43] C.W.V. Gmbh, C. Kgaa, Supporting Information, Adsorpt. J. Int. Adsorpt. Soc. (2012) 24. 
[44] H. He, J. Lin, W. Fu, X. Wang, H. Wang, Q. Zeng, Q. Gu, Y. Li, C. Yan, B.K. Tay, C. Xue, X. Hu, S.T. Pantelides, W. Zhou, Z. Liu, $\mathrm{MoS}_{2} / \mathrm{TiO}_{2}$ Edge-On Heterostructure for Efficient Photocatalytic Hydrogen Evolution, Adv. Energy Mater. 6 (2016) 1-7.

[45] X. Zhang, H. Tian, X. Wang, G. Xue, Z. Tian, J. Zhang, S. Yuan, T. Yu, Z. Zou, The role of oxygen vacancy- $\mathrm{Ti}^{3+}$ states on $\mathrm{TiO}_{2}$ nanotubes' surface in dye-sensitized solar cells, Mater. Lett. 100 (2013) 51-53.

[46] K. Lv, Q. Xiang, J. Yu, Effect of calcination temperature on morphology and photocatalytic activity of anatase $\mathrm{TiO}_{2}$ nanosheets with exposed $\{001\}$ facets, Appl. Catal. B Environ. 104 (2011) 275-281.

[47] B. Santara, P.K. Giri, K. Imakita, M. Fujii, Evidence of oxygen vacancy induced room temperature ferromagnetism in solvothermally synthesized undoped $\mathrm{TiO}_{2}$ nanoribbons, Nanoscale. 5 (2013) 5476-5488.

[48] J. Qu, Y. Ge, B. Zu, Y. Li, X. Dou, Transition-Metal-Doped p-Type ZnO NanoparticleBased Sensory Array for Instant Discrimination of Explosive Vapors, Small. 12 (2016) 1369-1377.

[49] A. V. Akimov, Y.S. Ganushevich, D. V. Korchagin, V.A. Miluykov, E.Y. Misochko, The EPR Spectrum of Triplet Mesitylphosphinidene: Reassignment and New Assignment, Angew. Chemie-Int. Ed. 56 (2017) 7944-7947.

[50] Y. Wang, Y. Zhang, J. Tang, H. Wu, M. Xu, Z. Peng, X. Gong, G. Zheng, Simultaneous Etching and Doping of $\mathrm{TiO}_{2}$ Nanowire Arrays for Enhanced Photoelectrochemical Performance, ACS Nano, 7 (2013) 9375-9383.

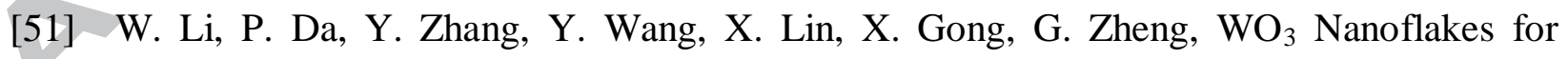
Enhanced Photoelectrochemical Conversion, ACS Nano, 8 (2014) 11770-11777. 


\section{Graphical Abstract}

\section{Hierarchical porous $\mathrm{TiO}_{2}$ single crystals templated from partly glassified polystyrene}

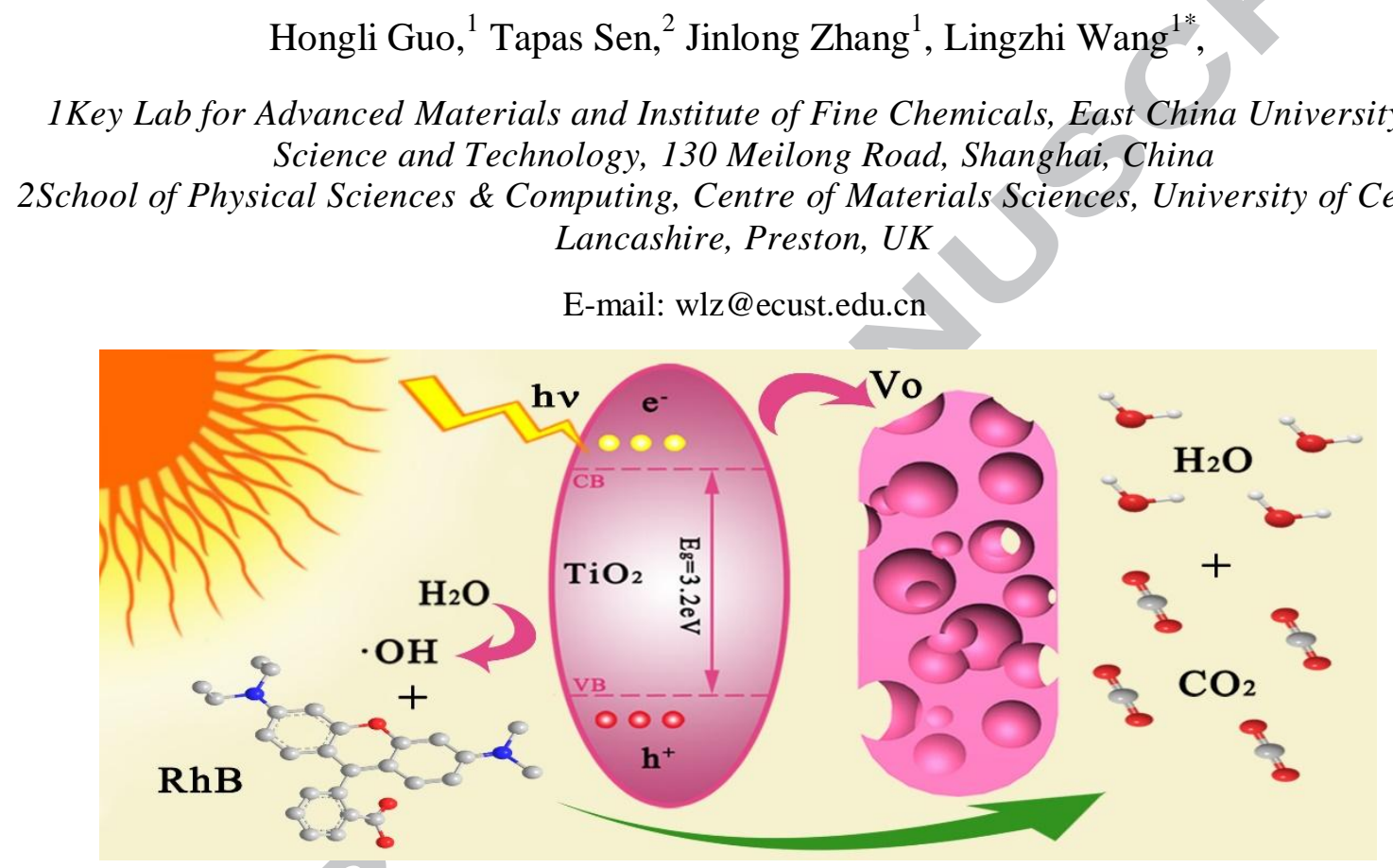

Hierarchical macro-mesoporous anatase $\mathrm{TiO}_{2}$ single crystal was one-pot synthesized using polystyrene (PS) as the single porogen. The key to the simultaneous growth of single crystal and the introduction of hierarchical pores is the assembly of PS and titania at the glassification temperature of PS, thus minimizing the interference from elastic PS on the oriental growth of $\mathrm{TiO}_{2}$ crystallite. The improved photocatalytic activity is a synergistic effect of improved separation of charge carrier and facilitated interfacial charge transfer benefitting from highly accessible porous single crystal structure. 